\title{
Massive Pneumoperitoneum after Endoscopic Argon Plasma Coagulation
}

Argon plasma coagulation is regarded as a safe method of electrocoagulation (1). We report here on a case illustrating the possible danger of argon plasma coagulation causing pneumoperitoneum due to occult perforation.

An 86-year-old woman with anemia (hemoglobin $7.9 \mathrm{~g} \%$ ) was seen for occult gastrointestinal bleeding. Colonoscopy showed angiodysplastic formations (Figure 1) at several sites, predominantly in the cecum. A hemorrhaging site was not found. The angiodysplasias were eradicated using argon plasma coagulation $(50 \mathrm{~W}$, gas flow $2 \mathrm{l} / \mathrm{min})$. Due to a transient submucosal emphysema at one coagulation site, six hours later a radiological check-up was carried out, which showed massive pneumoperitoneum (Figure 2). The patient remained without symptoms. Under treatment with prophylactic antibiotics and parenteral nutrition, she remained asymptomatic, and, after 14 days, the pneumoperitoneum had reduced by about $50 \%$.
Twenty-four days later, radiography showed full recovery from the pneumoperitoneum.

This case illustrates that argon plasma coagulation, despite noncontact electrocoagulation and the minimal coagulation depth, still harbors a risk of perforation. In their series, Grund et al. (1) noted a rate of about $0.31 \%$ of accidental perforation by argon plasma coagulation; all of the cases required laparotomy, and there was one fatality. Since the present patient showed no clinical symptoms, we used conservative treatment. Under antibiotic therapy, no signs of inflammation or peritonitis could be observed, and we were not forced to carry out a laparotomy. In a well-prepared colon, perforation does not seem to lead inevitably to infection, and thus does not need result in laparotomy.

The amount of intraperitoneal gas seemed to be larger than the argon gas volume used $(2 \mathrm{l} / \mathrm{min})$, which suggests that the air 
used to expand the colon played a major part in causing the pneumoperitoneum. Argon gas is not resorbed physiologically (2), and this explains the extended period for which the gas persisted intraperitoneally in this patient.

An in-vitro study (3) showed that an argon gas flow of $1-2.5 \mathrm{l} / \mathrm{min}$ should still be sufficient to allow the ignition process for argon plasma coagulation at high energy levels. The risk of perforation can be reduced by maintaining a safety distance of 3-7 mm (4) and using repeated suction to reduce the expansion of the intestines $(1,5)$. We believe that, in addition to these basic rules for argon plasma coagulation, it is important to keep the argon gas flow as low as possible, initially at $0.5 \mathrm{l} / \mathrm{min}$.

N. Hoyer, R. Thouet, U. Zellweger

Dept. of Internal Medicine and Endoscopy, Surselva Regional Hospital, Ilanz,

Graubunden, Switzerland

\section{References}

1. Grund KE, Zindel C, Farin G. Argonplasmakoagulation in der flexiblen Endoskopie. Bewertung eines neuen therapeutischen Verfahrens nach 1606 Anwendungen. Dtsch Med Wochenschr 1997; 122; 432-8.

2. Farin G, Grund KE. Technology of argon plasma coagulation, with particular regard to endoscopic applications. Endose Surg 1994; 2: 71-7.

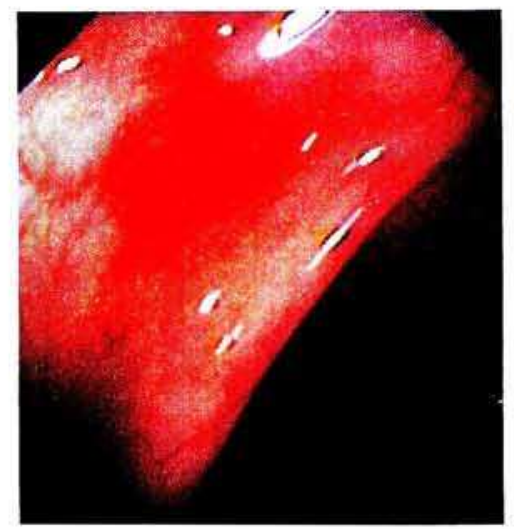

Figure 1: One of the angiodysplasias treated with argon plasma coagulation.

3. Johanns W, Jakobeit C, Luis W, Greiner L. Kontaktlose Argon-Gas-Koagulation in der flexiblen Endoskopie des Gastrointestinaltraktes: In-vitro-Untersuchungen und erste klinische Erfahrungen. Z Gastroenterol 1995; 33: 694700 .

4. Grund KE, Zindel C, Farin G. Praktische Hinweise für die Argonplasmakoagulation (APC) in der flexiblen Endoskopie. Endoskopie Heute 1996; $4: 338-44$.

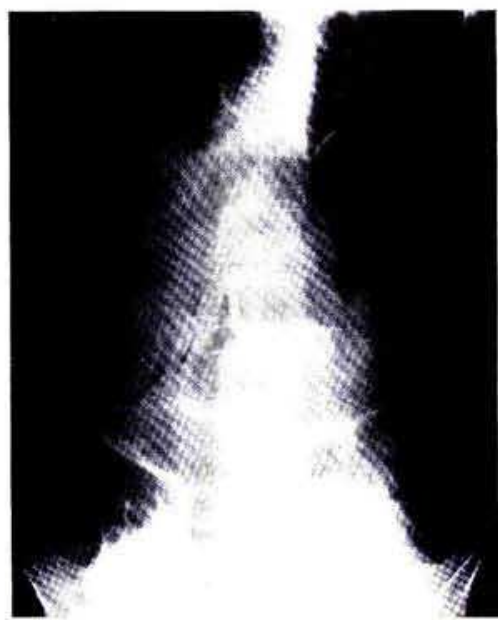

Figure 2: Massive pneumoperitoneum due to colonic perforation after argon plasma coagulation treatment.

5. Tan ACITL, Schellekens PPA, Wahab $\mathrm{P}$, Mulder CJJ. Pneumatosis intestinalis, retroperitonealis, and thoracalis after argon plasma coagulation. Endoscopy $1995 ; 27: 698-9$.

Corresponding Author

U. Zellweger, M.D.

Dept. of Internal Medicine Surselva Regional Hospital 7130 llanz, Graubunden Switzerland Fax: +49-81-92561 70 